ISSN: 2231-3354

Received on: 22-05-2012

Revised on: 09-07-2012

Accepted on: 13-09-2012

DOI: $10.7324 /$ JAPS.2012.2841

Lucky Lebgosi Nwidu

Department of Pharmacology and Toxicology, Faculty of Pharmacy, Niger Delta University, Wilberforce Island, Bayelsa State, Nigeria; P.O. Box 10935, Port Harcourt Nigeria

Paul Alozie Nwafor Department of Pharmacology and Toxicology, Faculty of Pharmacy, University of Uyo, Uyo, Akwa Ibom State, 520003, Nigeria

Wagner Vilegas

Department of Organic Chemistry, Chemistry Institute, São Paulo State University, UNESP-CP 355, CEP 14801-970, Araraquara, SP, Brazil

For Correspondence Lucky Lebgosi Nwidu P. O. Box 10935,

Port Harcourt,

Rivers state, Nigeria.

\section{Antiulcer Effects of Ethyl acetate Fraction of Carpolobia lutea Leaf}

\author{
Lucky Lebgosi Nwidu, Paul Alozie Nwafor and Wagner Vilegas
}

Keywords: Carpolobia lutea; Polygalaceae; cinnamoyl-, coumaroyl- 1-deoxyglucoside; ulcerogenic.

\section{INTRODUCTION}

The burden of non-communicable diseases account for $69 \%$ of all global deaths by 2030 with $80 \%$ of these deaths in low-income and middle-income countries (Samb et al., 2010). Approximately $50 \%$ (over 3 billion) of the world populations are known to be infected with Helicobacter pylori, mainly in the developing countries. Among those, hundreds of millions of people develop peptic ulceration during their lifetime and still tens of millions might progress to gastric cancer (Barik, 2009). Besides, approximately $60 \%$ of the world's population relies on plants for medication (Falbriant and Farnsworth, 2001) and plants have been the raw material for synthesis of many drugs and new therapeutic agents (Andreo et al., 2006). Traditional remedies world-wide are used to treat various gastric disorders since thousands of years (Gurbuz and Yesilada, 2007). Plants with divers chemical compounds possessing anti-ulcerogenic property have been reviewed (Lewis and Hanson, 1991). 
Polygalaceae is known to contain species with a variety polyphenolic compounds such as xanthones, flavonoids and biphenyl derivatives, which exhibit significant biological activities (Cervellati et al., 2004). The plant Carpolobia lutea (CL) is called cattle stick (English), Ikpafum (Ibibio), Agba or Angalagala (Igbo) and Egbo Oshunshun (Yoruba) in Nigeria (Etukudo , 2003; Muanya, 2008). The leaf is used to cure rheumatism, fever, pains, insanity, dermal infection, venereal diseases, sterility and to promote child birth. In addition, it is used as vermifuge and stomach medicine (Burkil, 1984; Muanya and Odukoya , 2008; Irvine, 1961). The stem bark is dried and taken as snuff to cure migraine headache (Irvine 1961) . The leaf is reported to have anti-inflammatory and anti-arthritis properties (Iwu and Ayanwu 1982) and to cure diabetes mellitus (Okon Etefia, Personal communication). Fever with diarrhea, headache, leprosy, snakebite, venereal disease and wounds are reported to be cured by the leaf extract (Lewis and Elvin-Lewis, 1977; Ajibesin et al., 2008).

The anti-diarrhoeal and anti-ulcerogenic potential of crude ethanolic extract of Carpolobia lutea leaf (CLL) have been established experimentally in rodents (Nwafor and Bassey, 2007). Preliminary evaluation of various fractions of the leaf extracts of CL revealed the ethyl acetate extract as the most gastro-protective (Nwidu and Nwafor, 2009). Although CLL is patronised traditionally for the management gastric ulcers and diabetes, the biological active molecules are yet to be elucidated. This work reports the single dose $(770 \mathrm{mg} / \mathrm{kg})$ protocol with cystaemininduced duodenal ulcer and evaluates the antiulcer effects of different doses of ethyl acetate fraction (EAF) in rodent. HPLC fingerprint of the EAF revealed the presence of polyphenolics in high concentration.

Polyphenolics are secondary metabolites, ubiquitous in the plant kingdom and are widely present in the human diet. They have shown to exert beneficial influence on human health (Manach et al., 2004). Phenolic compounds are potent antioxidants, and epidemiological studies have suggested a direct correlation between their high intake with diet and reduced risk of coronary heart disease mortality by suppressing the oxidation of low-density lipoprotein [19]. Cinnamic acid and p-coumaric acid antiulcer effects have been demonstrated (Frey et al., 2001; Pereira et al., 2003; Funari et al., 2007; Siddaraju and Shylaja, 2007; Barros et al., 2008). Two new cinnamoyl 1-deoxyglucosides, cinnamic acid, besides two new coumaroyl 1- deoxyglucosides, were isolated by semi-preparative HPLC and the structures was established using NMR experiments Nwidu et al., 2011.

This study quantitatively isolate, elucidate the active compounds from the EAF by semi-preparative HPLC and subjecting the fraction to radical scavenging assays (RSA). The total phenolic content (TPC) was also quantified.

\section{MATERIALS AND METHODS}

\section{Chemicals}

The chemicals used were all of analytical grade: absolute ethanol, ethyl acetate, chloroform, acetic acid (Reidel-de Haem, Germany), methanol (Synth, Brazil), cimetidine, omeprazole, propanolol, cystaemin hydrochloride, acetyl salicylic acids, indomethacin were all purchased from Sigma Chemical Co (St. Louis, USA).

\section{Preparation of Plant Material}

Carpolobia lutea leaves were collected and supplied by Mr. Okon Etefia, the traditional herbalist, attached to the Pharmacognosy Department, University of Uyo. The plant was identified and authenticated by Dr. (Mrs.) Margaret Bassey of Department of Botany, University of Uyo, Akwa Ibom State, Nigeria. A voucher specimen (UUH 998) was deposited at the University Herbarium, University of Uyo, Akwa Ibom State, Nigeria. The CLL was air dried under shade for 4 days at $30^{\circ} \mathrm{C}$, powdered with pestle and mortar. The pulverized leaves were stored at room temperature.

\section{Extraction, Fractionation and HPLC Analysis of C. lutea}

Procedure of gradient solvent extraction is as described in previous article (Nwidu and Nwafor, 2009) and fractionation as described in Nwidu et al.,2011. The HPLC analysis and isolation have been described (Rodrigues al., 2007; Latza et al.,1996; Hidradate et al., 2004). The structure elucidation of the isolated compounds is as reported in Nwidu et al., (2011).

\section{Determination of Total Phenolic Content (TPC)}

The TPC in CLL polar crude extract [crude ethanol extract (CETE) and crude ethyl acetate (CEAE)] and polar fraction [ethanol fraction (ETF) and ethyl acetate fraction (EAF)] were determined by Folin-Ciocalteu's (FC) reagent using the methods of Zeng and Wang 2001 and Liu et al.,2002 with modifications. Gallic acid was used as standard. This test was performed by preparing each extract and fraction with a concentration of 100 $\mu \mathrm{g} / \mathrm{ml}$. To $1 \mathrm{ml}$ solution of each extract (CEAE and CETE) and fraction (ETF and EAF) of $C$. lutea was added $1 \mathrm{ml}$ deionised water and $0.5 \mathrm{ml}$ of $1 \mathrm{~N} \mathrm{FC}$ solution and thoroughly shaken in a test tube and allow standing for 1 minute. Later, $1 \mathrm{ml}$ of $10 \%$ $\mathrm{Na}_{2} \mathrm{CO}_{3}$ solution was added and vortex for 30 seconds. This was allowed to stand for 40 minutes. The same treatment was giving to gallic acid. The standard absorbance of both extract and fractions were read on a spectrophotometer at $760 \mathrm{~nm}$. Blank samples without the test substances were prepared and the absorbance read also. For the analytical curve, $1 \mathrm{ml}$ of aliquots of 20, 40, 60, 80, $100,120,140,160,180,200,2200 \mu \mathrm{g} / \mathrm{l}$ aqueous gallic acid solution were used with $0.5 \mathrm{ml} 1 \mathrm{~N} \mathrm{FC}$ reagent. The linearlity and reproducibility of the analysis was determined from six replicates. The results were expressed as $\mathrm{mg}$ of gallic acid equivalent (GAE)/l.

\section{Determination of Antioxidant Activity with 1, 1 Diphenyl, 2- Picryl Hidrazyl (DPPH)}

The antioxidant potential was evaluated by spectrophotometric assay according to the method of Germano et al., 2002 in the visible region, using a solution of $0.004 \%$ DPPH in methanol, which was added to the solution of test samples. Stock solutions of extracts and standards were prepared to obtain a final 
concentration of $250 \mu \mathrm{g} / \mathrm{ml}$ (methanolic solution $20 \%$ Tween 80 ). Four standards samples were used: caffeic acid (CA), ferulic acid (FA) and gallic acid (GA). Each sample was prepared in a concentration of $5,10,20,40,80$ and $160 \mu \mathrm{g} / \mathrm{ml}$. Each sample (1 $\mathrm{ml}$ ) was added to $2 \mathrm{ml}$ of DPPH solution and after 30 minutes of reaction the absorbance of the solutions was measured at $517 \mathrm{~nm}$. The reference solution (blank) consisted of DPPH in solution of $20 \%$ Tween 80 . The spectrophotometer was calibrated with methanol. The sequestration of free radical activity of each sample was calculated by the inhibition of DPPH $\% \Delta$ (decrease in absorbance $)=\left(\mathrm{A}_{\mathrm{o}}-\mathrm{A} / \mathrm{A}_{\mathrm{o}}\right) \times 100,\left(\mathrm{~A}_{\mathrm{o}}=\right.$ absorbance of DPPH in methanol; $\mathrm{A}=$ absorbance of the sample after $30 \mathrm{~min}$ incubation). The values obtained were plotted on a graph of \% change in absorbance versus concentration of extract, fraction and standards.

\section{Animals}

Adult albino mice and rats were used. All the animals were housed in standard cages under laboratory conditions in the University of Uyo, Pharmacology department. The animals used were fed with pellet feeds (Vital Feed and Flour Mill Limited, Edo State, Nigeria) and water ad libitum. All animals used have free access to tap water under standard conditions of $12 \mathrm{~h}$ dark-12 h light and temperature $(21 \pm 1 \%)$. The protocols were approved by the University of Uyo Institutional animal Care and Use Committee (UUAEC) which follows the guidelines of the internationally accepted principles for laboratory animal use and care as found in the European Community guidelines (EEC Directive of 1986; 86/609/EEC).

\section{Determination of Median Lethal Dose $\left(\mathrm{LD}_{50}\right)$}

The median lethal dose $\mathrm{LD}_{50}$ was determined by the method of Lorke, 1983 with modification. The Swiss albino mice used in this study were starved for $24 \mathrm{~h}$ with free access to water except for $2 \mathrm{~h}$ prior to experiment. Different doses (100, 500, 1000, $1500,2000,2500,3000,3500,4000 \mathrm{mg} / \mathrm{kg}$ i.p.) of the ETF, EAF and CEAE were administered to nine group of mice $(n=3$ per dose) to establish the range of doses of the fraction and extract that would elicit toxic effects. The mice were observed for symptoms of toxicity and mortality intermittently for the next 6 hours if any and then again 24 hours post treatment for physical signs of toxicity. The $\mathrm{LD}_{50}$ was estimated by the geometric mean of the highest dose that caused $0 \%$ mortality and the lowest dose that cause $100 \%$ lethality.

\section{Pharmacological Assay}

Single dose $(770 \mathrm{mg} / \mathrm{kg})$ of CLL fractions ( $n$-hexane, chloroform, ethyl acetate and ethanol) were earlier evaluated using indomethacin-, ethanol-, reserpine in $0.5 \%$ acetic acid-, stress-, serotonin- and diethylthiocarbamate-induced ulcer models in rats. These assays were published in previous article Nwidu and Nwafor, 2007. In this work, we report the single dose fraction protocol with Cystaemin not published earlier in Nwidu and Nwafor, 2007. In addition, we report results of evaluation of three doses $(192.5,385.0$ and $770.0 \mathrm{mg} / \mathrm{kg}$ ) of EAF of CLL with indomethacin, ethanol and stress ulcer models. $20 \%$ of Tween 80 is used as vehicle for extract and fraction.

\section{Effect of Fractions on Cystaemin-Induced Duodenal Ulceration in Rats}

Male adult albino rats weighting between 113-123 g were used for this experiment. The rats were randomized and divided into 5 groups of 6 rats each. Food was withdrawn $24 \mathrm{~h}$ and water $2 \mathrm{~h}$ before the commencement of the experiment. Acute duodenal lesions were induced in rats using two doses cystaemin $300 \mathrm{mg} / \mathrm{kg}$ (p.o) in $1 \mathrm{ml}$ of distilled water at $4 \mathrm{~h}$ intervals. Group 1 was given $300 \mathrm{mg} / \mathrm{kg}$ (p.o) as positive control. Groups $2-5$ were pre-treated $0.5 \mathrm{~h}$ with $770 \mathrm{mg} / \mathrm{kg}$ CLL fractions of ethanol, ethyl acetate, chloroform and $n$-hexane, respectively before $300 \mathrm{mg} / \mathrm{kg}$ cystaemin. The CLL fractions were administered intragastrically via the aid of an orogastric cannula. 48 hours after the last dose of cystaemin, the animals were killed by cervical dislocation. The tissues were fixed with $10 \%$ formaldehyde in saline. The duodenum were removed and examined for lesion, the number and severity of gastric lesions and perforations were evaluated according to the procedure of Antonio et al., 2004.

\section{Effect of Ethyl Acetate Fraction on Indomethacin-Induced Gastric Ulceration in Rats}

Pilot tests aimed at determining the effective dose of indomethacin needed to produce reliable acute gastric ulceration in rats were evaluated using varying doses of indomethacin: 0.03, 0.06 and $0.1 \mathrm{~g} / \mathrm{kg}$ (b.wt.) on the rats. $0.1 \mathrm{~g} / \mathrm{kg}$ of indomethacin per body weight of animal produced gastric ulceration in all rats in $5 \mathrm{~h}$ in the pilot study. Male adult albino rats weighting $140-145 \mathrm{~g}$ were used for this experiment. The rats were randomized and divided into 5 groups of 6 rats each. Food was withdrawn $24 \mathrm{~h}$ and water $2 \mathrm{~h}$ before the commencement of the experiment. Group 1 (positive control) was administered with $0.1 \mathrm{~g} / \mathrm{kg}$ indomethacin, orally. Group $2-4$ were pre-treated with 192.5, 385.0, 770.0 $\mathrm{mg} / \mathrm{kg}$ EAF of CLL, respectively, $1 \mathrm{~h}$ prior to administration of 0.1 $\mathrm{g} / \mathrm{kg}$ of indomethacin. Group 5 received cimetidine $\left(1.0 \times 10^{-3}\right.$ $\mathrm{g} / \mathrm{kg}$, p.o) $1 \mathrm{~h}$ prior to administration of $0.1 \mathrm{~g} / \mathrm{kg}$ of indomethacin. The drugs were administered intragastrically via the aid of an orogastric cannula. $5 \mathrm{~h}$ later, the animals were killed by cervical dislocation. The stomach were removed and opened along the greater curvature. The tissues were fixed with $10 \%$ formaldehyde in saline. Macroscopic examination was carried out with the aid of a hand lens and scored for the presence of lesions using the method of Al-Said et al. 1986. Ulcer index (UI) of indomethacin alone, ulcer index and preventive ratio of each of the groups pre-treated with the EAF of CLL were calculated using the methods of AlSaid et al., 1986 and Nwidu and Nwafor, 2009.

\section{Effect of Ethyl Acetate Fractions on Ethanol-Induced Gastric Ulceration in Rats}

Male adult albino rats weighting between $215-225 \mathrm{~g}$ were used for this experiment. The rats were randomized and divided into 5 groups of 6 rats each. Food was withdrawn $24 \mathrm{~h}$ and water $2 \mathrm{~h}$ 
before the commencement of the experiment. Ulcer lesion was established with $0.5 \mathrm{ml}$ of $95 \%$ ethanol (p.o.). Group 1 was given ethanol as positive control, groups 2 - 4 were pre-treated with 192.5, $385.0,770.0 \mathrm{mg} / \mathrm{kg} \mathrm{EAF}$ of CLL, respectively, while group 5 received omeprazole $\left(3.0 \times 10^{-2} \mathrm{~g} / \mathrm{kg}\right.$, p.o $) 1 \mathrm{~h}$ prior to administration of $0.5 \mathrm{ml}$ of ethanol.

The three doses of EAF respectively were administered intragastrically via the aid of an orogastric cannula. The animals were killed $4 \mathrm{~h}$ later by cervical dislocation. The stomach were removed and opened along the greater curvature. The tissues were fixed with $10 \%$ formaldehyde in saline. Macroscopic examination was carried out with the aid of a hand lens and scored for the presence of lesions using the method of Barry et al., 1988. Ulcer index of ethanol alone, ulcer index and preventive ratio of each of the groups pre-treated with the EAF of CLL above and that of omeprazole (standard drug) were calculated using the method of Zaidi and Mukerji, 1958.

\section{Effects of Ethyl Acetate Fractions on Water Immersion- Induced Gastric Ulceration in Rats}

Male adult albino rats weighting 215-223 g were used for this experiment. The rats were randomized and divided into 5 groups of 6 rats each. Food was withdrawn $24 \mathrm{~h}$ and water $2 \mathrm{~h}$ before the commencement of the experiment. Group 1 (positive control) rats were placed individually in plastic cages measuring $5.0 \times 5.0 \times 30.0 \mathrm{~cm}$. The animals were placed individually in each compartment of the cage and it was immersed vertically in water tank, water was added gradually to the level of the xiphoid. The temperature of the tank was maintained at $15-20{ }^{\circ} \mathrm{C}$ using ice pack to induce stress ulceration.

Group 1 was immersed in water without administration of the test samples. Group 2-4 were pre-treated with 192.5, 385.0 and $770.0 \mathrm{mg} / \mathrm{kg}$ of the EAF of CLL respectively, $1 \mathrm{~h}$ prior to immersion. While group 5 received cimetidine $\left(1.0 \times 10^{-3} \mathrm{~g} / \mathrm{kg}\right.$, p.o) $1 \mathrm{~h}$ prior to immersion. The drugs were administered intragastrically via the aid of an orogastric cannula. $18 \mathrm{~h}$ later, the animals were killed by cervical dislocation. The stomach were removed and opened along the greater curvature. The tissues were fixed with $10 \%$ formaldehyde in saline. Macroscopic examination was carried out with the aid of a hand lens and scored for the presence of lesions using the methods of Takalgi and Okabe (1968). Ulcer index (UI) of rats immersed in water without drug alone, ulcer index and preventive ratio of each of the groups pretreated with the EAF of CLL were calculated using the method of Takalgi and Okabe (1968). The number and severity of gastric lesions were evaluated according to the following rating scale.

\section{Statistical Analysis and Data Evaluation}

Data obtained from this work were analysed statistically using Students' T-test and by multiple comparisons of Mean \pm S.E.M by one way and two way analysis of variance (ANOVA, One- or Two -way) followed by a post test (Turkey- Kramer multiple comparison test). A probability level of less than $5 \%$ was considered significant $(\mathrm{P} \leq 0.05)$.

\section{RESULTS}

Determination of Total Phenolics Content (TPC)

The quantification of TPC for the polar extract and fractions revealed that the percentage of TPC increased from 61.33, 78.67, and 90.78 to $136.22 \mu \mathrm{g} / \mathrm{ml}$ for ETF, EAF, CEAE and CETE of CLL respectively (Figure 1).

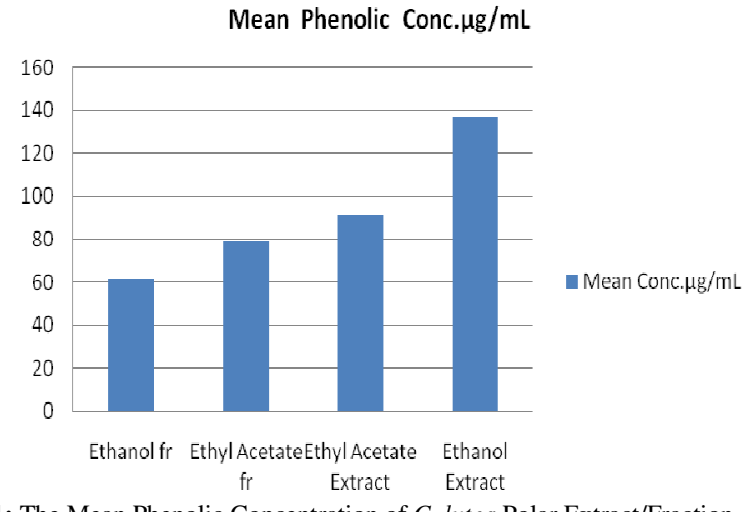

Fig. 1: The Mean Phenolic Concentration of $C$. lutea Polar Extract/Fraction.

\section{Determination of Antioxidant Activity with DPPH}

The antioxidant activity of the $C$. lutea fractions and extract showed minimal radical scavenging activity when compared to standard (Figure 2).

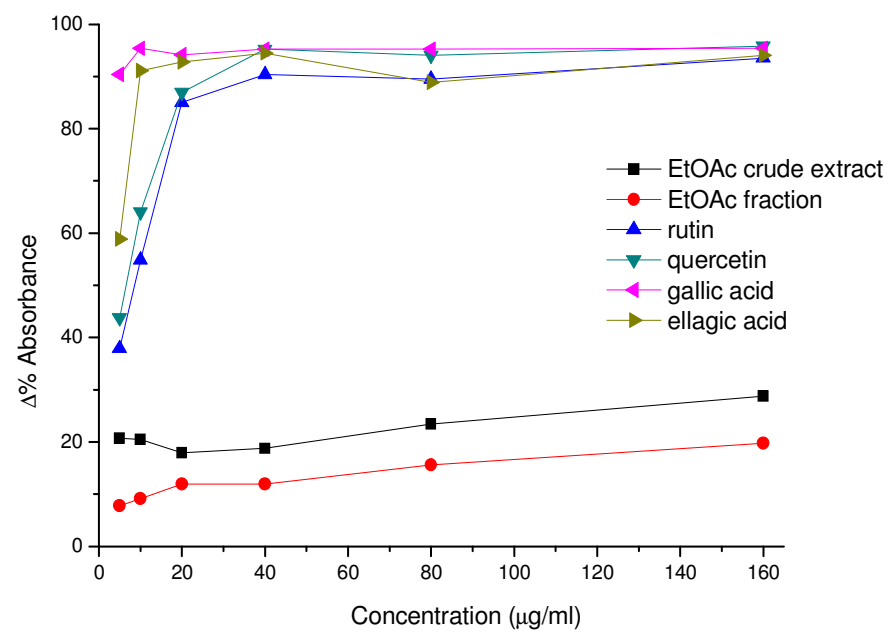

Fig. 2: Antioxidant Activity of $C$. lutea Leaf Fraction with DPPH.

\section{Determination of Median Lethal Dose $\left(\mathbf{L D}_{\mathbf{5 0}}\right)$}

The acute toxicity study $\mathrm{LD}_{50}$ shows that median lethal dose is $3850.0,3240.4$ and $1414.2 \mathrm{mg} / \mathrm{kg}$ for the ETF, CETE and EAF, respectively. The signs of toxicity were observed from 1250 $\mathrm{mg} / \mathrm{kg}, 3000 \mathrm{mg} / \mathrm{kg}$ and $3100 \mathrm{mg} / \mathrm{kg}$ for the EAF, ETF and CETE respectively. The mortality rate was observed from 1750,3600 and $3200 \mathrm{mg} / \mathrm{kg}$ and rose to 2000,4000 and $3500 \mathrm{mg} / \mathrm{kg}$ for the EAF, ETF and CETE respectively. The no observed-adverse-effect level (NOAEL) for the intraperitoneal dose was $1500 \mathrm{mg} / \mathrm{kg}$ and the lowest-observed-adverse-level (LOAEL) $3000 \mathrm{mg} / \mathrm{kg}$. Signs of toxicity observed include restlessness, convulsion, salivation, defecation, urination, syncope, asthenia and death under $24 \mathrm{~h}$ doses. 


\section{Evaluation of Antiulcer Activity}

The results of the antiulcer assays using these protocols are enumerated as follows:

\section{Effect of CLL Fraction on Cystaemin-Induced Duodenal Perforation in Rats}

The treatment with $770 \mathrm{mg} / \mathrm{kg}$ CLL fractions (ETF, EAF, $\mathrm{CHF}$ and $n$-HF) do not significantly reduced the ulcer index relative to control group $(\mathrm{P} \geq 0.05)$. The preventive ulcer ratios are $32.64,77.11,55.79,67.46$ and 46.58 for the treated group with 770 $\mathrm{mg} / \mathrm{kg}$ CLL fraction (ETF, EAF, CHF and $n$-HF) and famotidine, respectively as shown in Figure 3.

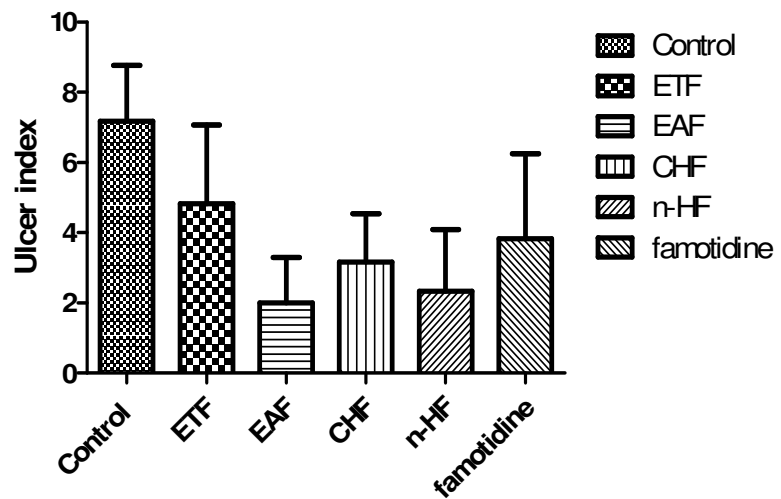

Fig. 3: Effects of CLL Fractions on Cystaemin- induced Ulceration in Rats Significance relative to control: Not significant, values represent mean \pm S.E.M $(\mathrm{n}=6)$

\section{Effects of EAF of CLL on Indomethacin-Induced Ulceration in Rats}

The result of gradient doses CLL EAF on indomethacininduced ulceration in rat shows the median and the lowest dose to exert significant preventive ratio than the highest dose of the fraction. Pre-treatment with EAF (192.5-770 mg/kg) show the median and lowest dose statistically significant $(\mathrm{p}<0.001)$ relative to control. The lowest dose followed by the median dose exhibit the highest antiulcer effect. The result is shown in Figure 4.

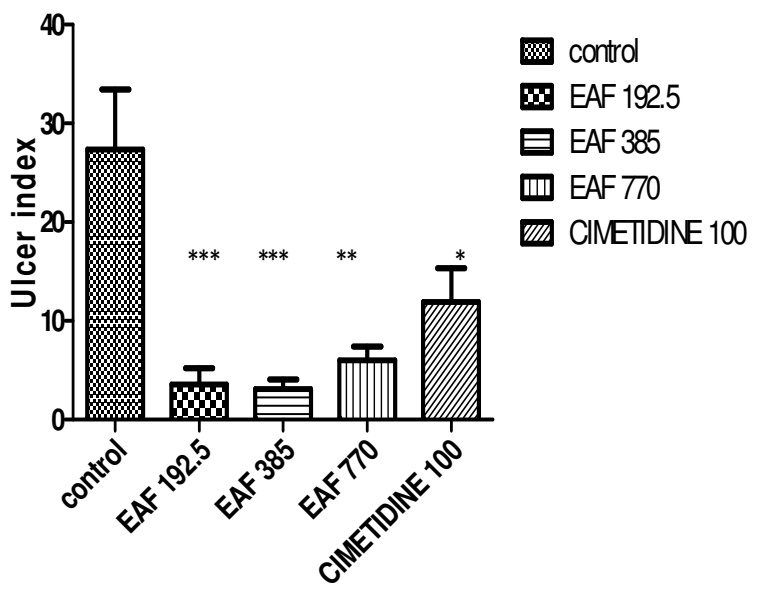

Fig. 4: Effects of EAF of CLL on Indomethacin-induced Ulceration in Rats. Significance relative to control: $* \mathrm{p}<0.05 ; * * \mathrm{p}<0.01 ; * * * \mathrm{P}<0.001 ; \quad$ values represent mean \pm S.E.M $(n=6)$.
Effects of EAF of CLL on Ethanol-Induced Ulceration in Rats

The result shows that pre-treatment with CLL EAF at doses of $192.5,385$ and $770 \mathrm{mg} / \mathrm{kg}$ and omeprazole $(30 \mathrm{mg} / \mathrm{kg})$ significantly $(p<0.001)$ reduced ulcer lesions. The ethyl acetate fraction dose-dependently decreased the severity of lesions by 93 , 93, 100 and $68 \%$, respectively. Ethyl acetate fraction $(770.0$ $\mathrm{mg} / \mathrm{kg}$ ) of $C$. lutea showed significant gastric protection than the positive control drug (omeprazole). The result is shown in Figure 5 .

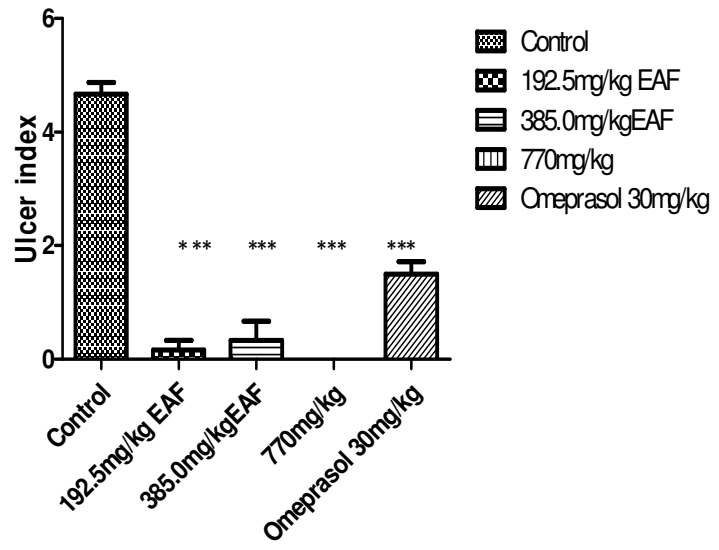

Fig. 5:

Effects of EAF of CLL on Ethanol-induced ulceration in rats. Significance relative to control: $* * * \mathrm{P}<0.001$; values represent mean \pm S.E.M $(\mathrm{n}=6)$.

\section{Effect of $C$. lutea Leaf Fractions on Stress-Induced (Water Immersion) Ulceration in Rats}

The result shows that CLL EAF (192.5, 385.0, 770.0 $\mathrm{mg} / \mathrm{kg})$ and cimetidine $(100 \mathrm{mg} / \mathrm{kg})$ produce a dose dependent and significant reduction $(\mathrm{P}<0.001)$ of the ulcer index as shown in Figure 6.

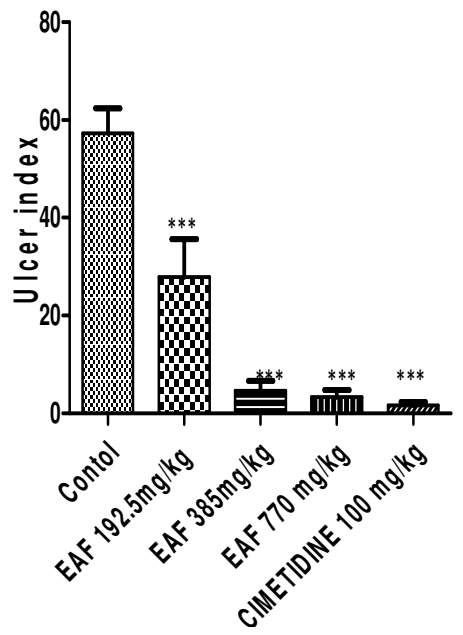

Conto

B EAF $192.5 \mathrm{mg} / \mathrm{kg}$

三 EAF $385 \mathrm{mg} / \mathrm{kg}$

IIII EAF $770 \mathrm{mg} / \mathrm{kg}$

UIM CIMETIDINE $100 \mathrm{mg} / \mathrm{kg}$

Figure 6. Effects of EAF of CLL on Stress-induced (Water Immersion) Ulceration in Rats.

Significance relative to control: $* * * \mathrm{P}<0.001$; values represent mean \pm S.E.M $(\mathrm{n}=6)$.

\section{DISCUSSION}

Dietary polyphenols has protective effects against various degenerative diseases (Scalbert et al., 2004; Manach and Scalbert, 2005) and posses' antiulcer activity (Saito et al., 1988; Siddaraju and Shylaja, 2007b). Several phenolics compound have antiulcer 
properties in rats (Sairam et al., 2002). Caffeic, ferulic, $p$-coumaric and cinnamic acids have demonstrated significant antiulcer activity (Barros et al., 2008 ). Phenolic acids play a major role in down regulating parietal cell $\mathrm{H}^{+}, \mathrm{K}^{+}$-ATPase with cinnamic acid and $p$ coumaric exhibiting maximum inhibitory activity. They also inhibit ulcerogen- $H$. pylori- and exhibit anti-oxidative properties in vitro (Barros et al., 2008; Das et al., 1997). Oxidative stress is considered a common factor in the pathogenesis of ulcers in different experimental and clinical models (Das et al., 1997). The antioxidant activity of phenolics is associated to antiulcer activity because free radicals and ROS are the main causative factors for ulcer (Saito et al., 1988)[43]. Rajan et al., (2001) and Hung et al., (2005) demonstrated the strong antioxidant activity of phenolic acids and analogues. Besides, cinnamic acid is reported the best inhibitor of Helicobacter pylori (Siddaraju and Shylaja, 2007b). Therefore the isolation and characterisation of cinnamoyl- and coumaroyl- 1-deoxyglucosides from the most antiulcer active fraction, EAF, could support the observed antiulcer properties. Free-radical-mediated cell injury and lipid peroxidation in various pathological phenomena have been reported (Halliwell, 1987). Numerous antioxidant methods and modifications have been proposed to evaluate antioxidant activity and to explain how antioxidants function. Of these, total antioxidant activity, reducing power, DPPH assay, metal chelating, active oxygen species such as $\mathrm{H}_{2} \mathrm{O}_{2}, \mathrm{O}_{2}{ }^{-}$and $\mathrm{OH}^{\circ}$ quenching assays are most commonly used for the evaluation of antioxidant activities of extracts (Amarowicz et al., 2000; Chang et al., 2002).

In our study, we used DPPH test/method which is one of the oldest and most frequently used methods for total antioxidant potential/capacity of food extracts. DPPH is a stable free radical and is often used to evaluate the antioxidant activity of several natural compounds (Yokozawa et al., 1998). Antioxidants, on interaction with DPPH, transfer electron or hydrogen atom to DPPH, and thus neutralize its free-radical character. DPPH shows a strong absorption at $517 \mathrm{~nm}$. It's mechanism of action is based on the ability of an antioxidant to give hydrogen radical to synthetic long-lived nitrogen radical compound DPPH. A blue violet colour changes gradually to green and yellow (absorption maximum at $405 \mathrm{~nm}$ ), and a decrease in absorbance at $517 \mathrm{~nm}$ is monitored. However, in our study, the RSA of the fraction was less than the extract. The RSA of both extract and fraction was less than $20 \%$. This entails that the extract and fraction lack compounds which could donate either hydrogen or electron to DPPH. The RSA of fraction and extract was quite below that of caffeic acids, ferrulic acids and galic acids which are above $90 \%$. The aromatic hydroxyl group plays a considerable antioxidative role by conferring stability to the radical form and participating in electron delocalization. Compounds with aromatic hydroxyl groups may be few in the extract and fraction as revealed by trans-cinnamic acids glucosides, the major isolated compounds from the EAF. The trans-cinnamic glucosides isolated (constitute $21.9 \%$ of isolated compounds) function as Michael's electron acceptor and could not donate electron to reduce DPPH, hence the low RSA. Therefore, DPPH assay is not able to elucidate the mechanism of antioxidant activity of CLL as observed. The antioxidant activity of putative antioxidants have been attributed to various mechanisms, among which are prevention of chain initiation, binding of transition metal ion catalysts, decomposition of peroxides, prevention of continued hydrogen abstraction, reductive capacity and radical scavenging (Oktay et al., 2003). The HPLC profiling of the extract and fraction reveal preconcentration of the polyphenols in EAF than the aqueous crude extract. Trans-cinnamic acids glucosides constitute $21.9 \%$ of these polyphenols in EAF. Present evaluation of the polar fractions and crude extract revealed the concentration of TPC to be $61.33,78.67,90.78$ and $136.22 \mu \mathrm{g} / \mathrm{ml}$ for ETF, EAF, CEAE and CETE, respectively. The crude extract is richer in polyphenolic than the fraction. This result may in part be due to the presence in the crude extract many different phenolics components that were not isolated by EAF during the fractionation process. Different mechanisms have been proposed for the pathogenesis of cysteamin-induced gastrointestinal ulcer such as hypersecretion of gastric acid, reduced bicarbonate secretion in response to acid in duodenum and delayed gastric emptying (Szabo, 1987; Szabo, 1978; Poulsen et al., 1985).The results obtained shows that CLL EAF inhibited the formation of duodenal ulcer. This effect might be due to gastric acid inhibition or neutralization in the stomach or due to stimulation of the formation of mechanical adherent barrier (mucus) by EAF in the duodenum. Other possible mechanisms reported in literature are by stimulation of epidermal growth factor (EGF), endothelium-derived relaxing factor (nitric oxide) and nonprotein sulfydryl derivatives, all are involved in maintaining the integrity of the mucosa (Salim, 1989; Donadel et al.,2005). It is also possible that the inhibition of gastric acid secretion and the mucus release in the duodenal mucosa may indirectly interfere with duodenal mucosa protection, thus maintaining its integrity. However, the exact mechanism of inhibition duodenal mucosa perforation is unknown but may not be unrelated to any of these reported mechanisms of maintaining gastric mucosal integrity. These results, taken together, suggest that the EAF may act by any of these mechanisms. However, other mechanisms may also be involved. Non-steroidal anti-inflammatory drugs such as indomethacin have the ability to cause gastroduodenal ulceration, and this effect is related to the ability of these agents to suppress prostaglandin synthesis (Wallace 2001). The gastrointestinal irritant property of indomethacin is the major impediment to their use as anti-inflammatory drugs (Chiba et al., 2008). Indomethacin inhibits prostaglandin production, increased acid production and decreased cytoprotective mucus formation leading to gastrointestinal ulcer (Wallace 2005; Hiruma-Lima 2009). The lower and middle dose of EAF were quite effective than the highest dose. This may be as a result of the higher dose of the extract exhibit pro-oxidant effects. That the EAF of CLL inhibited indomethacin - induced ulceration therefore suggests that it may partly mediate its effect through cyclo-oxygenase pathway. This finding indicates that active compounds present in EAF may enhance either gastric mucosal defensive factor and are effective than $\mathrm{H}_{2}$-receptor antagonists, cimetidine, the standard drug utilised in this assay. 
Ethanol-induced ulcers predominate in the glandular part of the stomach, stimulate the formation of leukotriene $\mathrm{C}_{4}\left(\mathrm{LTC}_{4}\right)$ and result in the damage of rat gastric mucosa (Drelying et al., 1986; Cho et al., 1987). Ethanol-induced gastric lesions caused superficial damage to mucosal cells resulting in gastric mucosal change which may in part due to free radical formation (Oates and Hakkinen 1988), increase in lipid peroxidation and decrease of the levels of protein sulphydryl compounds in gastric mucosa (Mui and Doteuchi 1986). Ethanol is metabolized in the body to cause increased production of $\mathrm{O}^{2}$ - within the tissues, and simultaneously increased free radical concentration. This free radical causes denaturation of DNA strands and protein; reduce gastric blood flow, haemorrhage, necrosis and solubilisation of mucus constituents in the stomach. These actions result in an increased flow of $\mathrm{Na}^{+}$and $\mathrm{K}^{+}$, increased pepsin secretion, and a loss of $\mathrm{H}^{+}$ ions and histamine into the lumen (Szabo, 1987). It is also established that disturbances in gastric secretion, damage to gastric mucosa, alterations in permeability, gastric mucosa depletion and free radical production are observed after administration of ethanol (Salim 1990). Ethanol is one of the ulcerogenic agents that induce intense damage in gastric mucosa by promoting disturbances of mucosal microcirculation, ischemia and appearance of free radicals, endothelin release, degranulation of mast cell and inhibition of prostaglandins and decrease of gastric mucus production (Abdel-Salam et al., 2001). All the doses of EAF utilised in the experiment were very effective than the $30 \mathrm{mg} / \mathrm{kg}$ omeprazole. At a critical dose of $770 \mathrm{mg} / \mathrm{kg}$, the same dose that gave 100\% inhibition of intestinal transit (Nwidu et al., 20011), the ulcers induced by ethanol were protected $100 \%$. The low RSA may preclude DPPH assay as a possible mechanism of elucidating its antioxidant effects.

Stress plays an important role in the etiopathology of gastroduodenal ulceration (Favier et al., 2005). Recently, oxygenderived free radicals have been postulated to play an important role in the pathogenesis of acute gastric mucosal injuries such as those induced by stress (Govindarajan et al., 2006), ethanol (Salim, 1990) and NSAIDs (Pihan et al., 1987). Scavenging these radicals stimulates the healing process. It is well known that stress stimulates various damaging pathways, causing increased production of reactive oxygen species (ROS), such as hydrogen peroxide, hydroxyl radicals and superoxide anion radical, which lead to lipid peroxidation, protein oxidation, DNA damage and cell death, and contributes to the occurrence of pathological conditions (Liu et al., 1996; Liu and Mori 1999; Heise et al., 2003). However, in our study, the RSA of the fraction is below $20 \%$, oxygen derived free radicals may play significant role but the DPPH assay could not be implicated as a plausible mechanism of elucidating the antioxidant activity of the fraction. Stress - induced gastric lesion is characterized by increase in gastric acid and peptic secretion; decrease in gastric blood flow; suppression of endogenous generation of prostagladins; inhibition of mucosal growth and cell proliferation; and alteration of gastric motility (Konturek et al., 1986a; Konturek et al., 1986b; Soll 1983). Gastric stress-induced ulcer is probably mediated by the release of histamine. It not only increases gastric secretion, often called the aggressive factor, but also causes disturbances of the gastric mucosal microcirculation and abnormal motility, and reduces mucus production, known as the defensive factor. Moreover, stress-induced ulcer in animal models may be partially or entirely prevented by vagotomy, since increased vagal activity has been suggested as the main factor in stress-induced ulceration (Singh and Majumdar 1999). The vagus nerve stimulates stomach acid secretion via interaction of its chemical mediator (acetylcholine) with the muscarinic receptor. The activation of the muscarinic receptor gives rise to sequential events that result in increased gastric acid secretion (Clapham 1995). According to some authors, those receptors are located in the parietal cells and histamine secretary cells. Therefore, the increase in acid secretion is a consequence of acetylcholine activity on the histamine cell and parietal cell activity (Schubert 2000). It is important to consider that vagal activity is up regulated in situations of stress. Some antiulcer drugs, such as cimetidine, ranitidine and famotidine, are used in ulcer treatment by blocking $\mathrm{H}_{2}$ histaminic receptors. Moreover, it is important to state that $770 \mathrm{mg} / \mathrm{kg}$ dose of EAF reduced ulcer index comparable to the standard drug, cimetidine $(100 \mathrm{mg} / \mathrm{kg})$. At that same dose of the fraction in another study, the intestinal propulsive movements (IPM) in rat was inhibited by $100 \%$ through $\alpha_{2^{-}}$adrenergic mechanism (Nwidu et al., 2011). Thus the possible mechanism of antiulcer activity may not be unrelated with the inhibition muscarinic receptors in the parietal cells.

C. lutea fractions interrupt diethyldithiocarbamate (DTC) induces antral lesions in earlier report by $68.79 \%$ (Nwidu and Nwafor 2009). DTC is reported to initiates its effects by mobilization of superoxide and hydroxyl radicals (oxygen derived free radicals) (Oka et al., 1990). Superoxide radical and hydrogen peroxide play pathogenic role in this ulcer model Salim (1989). The low RSA observed in our study could not be explained in light of present findings. Gastric cyto-protection may be mediated by at least two different mechanisms. The first one is by stimulation of release of prostaglandins (PG) and the second one by Michael's acceptor interaction with sulfhydryl-containing compounds of the mucosa. The latter, mechanism of cyto-protection might be mediated by CLL EAF, at least in part, by the reaction between electrophilic moiety on the trans-cinnamic acid and sulfhydrylcontaining compounds of the gastric mucosa (Donadel et al., 2005). In this mechanism of cyto-protection, antioxidant activity might be mediated by the reaction between the electrophilic acceptor, trans-cinnamic acid, (which constitute $21.9 \%$ of isolated compounds) from the EAF with sulfhydryl-containing compounds of the gastric mucosa (Maria et al., 2000)[79]. Trans-cinnamic acid (Michael's acceptor) and electron donation by sulphydryl moiety present in proteins or oxidants containing compounds has form a new basis of cytoprotection (Souza-Brito et al., 1998; HirumaLima et al., 1999; Hiruma-Lima et al., 2001; Melo et al., 2003; Yesilada et al., 2004; Hamauzu et al., 2008).

These results, taken together, suggest that the EAF active compounds mechanism of RSA is yet to be elucidated; but may be 
mediated by trans-cinnamic acid (Michael's acceptor) interaction with oxidants. This assertion is predicated on the significantly large amount of trans-cinnamic acids in the isolated compounds. The antioxidative activity of trans cinnamic acid like any caffeic acid analogue, depends on several other factors such as: unsaturated 2,3-double bond of the side chain (which maximizes the stabilization of the phenolic radical), the electron-donating and withdrawing substituent on the catechol ring, the number of hydroxyl groups or catechol moieties, the involvement of other $\mathrm{H}-$ donating groups (-NH, -SH), the chemical stability, and the hydrophobicity or partition coefficient $(\log P)$ of the compounds (Rice-Evans et al., 1986). However, other mechanisms may also be involved. The antiulcer assays with isolated compounds need further evaluation to elaborate possible mechanism of antiulcer effects.

\section{CONCLUSION}

The demonstration of inhibition of acute antiulcer models couple with the characterisation and isolation phenolics with reported antiulcer potential gave credence to $C$. lutea folkloric patronage as stomach medicine. However, the explicit antiulcer mechanism of the $C$. lutea leaf fractions is non-specific in nature, evident by the various ulcerogenic agents it inhibited. Though two cinnamoyl 1-deoxyglucopyranosides and two new $p$-coumaroyl 1deoxyglucopyranosides, besides cinnamic acid were isolated and characterised, further bioactivity guided evaluation of these new molecules may lead to a novel antiulcer drug discovery.

\section{ACKNOWLEDGEMENTS}

This study was supported by Niger Delta University Postgraduate Fellowship. Khana Local Government Council, Ogoni, supported the predoctoral fellowship with part payment for airfare; FAPESP provided stipends for accommodation at UNESP, Araraquara, São Paulo, Brazil. Dr. Viviani Candida da Silva and Dr. Clinelsom Martins Rudriques provided technical assistance in the spectroscopic and chromatographic analysis.

\section{REFERENCES}

Abdel-Salam OM., Czimmer J., Debreceni A., Szolcsányi J., Mózsik G. Gastric mucosal integrity: gastric mucosal blood flow and microcirculation. J. Physiol (Paris) 2001; 95: 105-127.

Ajibesin KK., Ekpo AB., Bala DN., Essien EE., Adesanya SA. Ethnobotanical survey of Awa Ibom State of Nigeria. J. Ethnopharmacol 2008; 115: 387-408.

Al-Said MS., Ageel AM., Parmar NS., Tariq M. Pharmacological studies on the antiulcerogenic activity of Chinese Cinnamon. Planta Medica 1986; 6:440-443.

Amarowicz R., Naczk M., Shahidi F. Antioxidant activity of crude tannins of canola and rapeseed hulls. J. Amer Oil Chemist's Soc 2000; 77: 957-961.

Andreo MA., Ballesteros KVR., Hiruma-Lima CA., Rocha LRM., Brito-Souza ARM., Vilegas W. Effects of Mouriri pausa extracts on experimentally induced gastric lesions in rodents: endogenouse sulhydryls compounds and nitric oxide in gastroprotection. J. Ethnopharmacol 2006; 107 (3): 431-41.

Antonio JM., Gracioso JS., Toma W., Lopez LC., Oliveira F., Souza Brito ARM. Antiulcerogenic activity of ethanol bextract of Solanum variable ( false “jurubeba”) J. Ethnopharmacol 2004; 93: 83-88.
Barik AS. Helicobacter pylori Infection in Developing Countries: The Burden for How Long? Saudi J. Gastroenterol 2009; 15 (3): 201-207.

Barros PB., Lemos M., Maistro EL., Leite MF., Sousa JPB., Bastos JK., Andrade SF. Evaluation of antiulcer activity of the main phenolic acids found in Brazillian Green Propolis. J. Ethnopharmacol 2008; 120: 372-377.

Barry CN., Proutau M., Lloyd KG. Salphasalmino and Phci $28 \mathrm{~A}$ inhibit the formation of ethanol and phenylbutazone-induced rat gastric ulcers. Lack of involvement of endogenous prostaglandins. British J. Pharmacol 1988; 93: 465-472.

Burkill HM. The Useful Plants of West Tropical Africa (vol. 1, 2nd ed.). Royal Botanic Gardens, Kew, UK: Family A-D; 1984; p. 1-960.

Cervellati R., Innocenti G., Dall'Acqua S., Costa S., Sartinia E. Polyphenols from Polygala spp. And their Antioxidant Activity. Chem Biod 2004; 1: 415-417.

Chang LW., Yen WJ, Huang SC., Duh PD. Antioxidant activity of sesame coat. Food Chem 2002; 78: 347- 354.

Chiba T., Sato K.., Kudara N., Shinozaki H., Ikeda K., Sato K., Endo M., Orii S., Suzuki K. Upper gastrointestinal disorders induced by non-steroidal anti- inflammatory drugs. Inflammopharmacol. 2008; 16:1620 .

Cho CH., Ogle CW., Sevila EI.Protection of sulphasalazine against ethanol-induced gastric damages in rats. Brit. J. Pharmacol 1987; 92: 31-38.

Clapham DE. Calcium signalling. Cell 1985; 80: 259-268.

Das D., Bandyopadhyay D., Bhattacharjee B., Banerjee RK.. Hydroxy radical is the major causative factor in stress induced gastric ulceration. Free Radical Biol Med 1997; 23: 8-18.

Donadel OJ., Guerreiro E., Marı́a AO., Wendel G, Enriz RD, Oscar S., Giordano OS., Tonn CE. Gastric cytoprotection activity of ilicic aldehyde: structural activity relationships. Bioorg Med Chem Lett 2005; 15:3547-3550.

Drelying KW., Lange K.., Peskar BA., Peskar BM. Release of leucotrienes by rat and human gastric mucosa and its pharmacological modification. Proceedings Supplement 1986; 88: 236.

Etukudo I. Ethnobotany: Conventional and Traditional Uses of Plants. Nigeria: The Verdict Press; 2003, p.111.

Falbriant DS., Farnsworth NR. The Value of Plants Used in Traditional Medicine for Drug Discovery. Env Health Persp 2001; 109 (1): 69-105.

Favier L.S., María A.O.M., Wendel G.H., Borkowski E.J., Giordano O.S., Pelzer L., Tonn C.E. (2005). Anti-ulcerogenic activity of Xanthanolide Sesquiterpenes from Xanthium cavanillesii in Rats. J. Ethnopharmacol 100: 260-267.

Frey RS., Li J., Singletary KW. Effects of genistein on cell proliferetion and cell cycle arrest in neoplastic human mammary epithelial cells: involvement of Cdc2, p21waf/cipl, p27kipl, and Cde2C expression. Biochem Pharmacol 2001; 61, 979-989.

Funari CS, Ferro VO, Mathor MB. Analysis of propolis from Bacharis Dracunculifolia DC. (Compositae) and its effect on mouse fibroblasts. J. Pharm Pharmacol 2007; 59: 463-68.

Germano, MP., Pasquale R., D' Angelo V., Catania S., Silvari V., Costa C. Evaluation of extracts and isolated fraction from Capparis spinosa L. buds as antioxidant source. J. Agric Food Chem 2002; 50 (11) : 68-71.

Govindarajan R., Vijayakumar M., Singh M., Rao CV., Shirwaikar A., Rawat AKS., Pushpangadan P. Antiulcer and antimicrobial activity Anogeissus latifolia. J. Ethnopharmacol 2006; 106: 57-61.

Gurbuz L., Yesilada E. Evaluation of the antiulcerogenic effect of sequiterpines lactone from Centaurs soltstitialis L. J. Ethnopharmacol 2007; 112: 284-291.

Halliwell B. Oxidants and human disease: some new concepts. FASEB J 1987; 1: 358-364.

Hamauzu Y., Irie M., Kondo M., Fujita T. Antiulcerative properties of crude polyphenols and juice of apple, and Chinese quince extract. Food Chem 2008; 108: 488-495.

Heise K., Puntarulo S., Portner HO., Abele D. Production of reactive oxygen species by isolated mitochondria of the Antartic bivalve 
Laternula elliptica (King and Broderip) under heat stress. Comp. Biochem Physiol Toxicol Pharmacol 2003; 134: 79-90.

Hidradate S., Morita S., Sugie H., Fuji Y., Harada J. Phytotoxic cis-cinnamoy glucosides from Spiraea thumbergii. Phytochem 2004; 65: 731-739.

Hiruma-Lima CA., Batista LM., de Almeida ABA., de Pietro ML., Santos, LC., Vilegas W., Souza- Brito ARM. Antiulcerogenic action of ethanolic extract of the resin from Virola surinamensis Warb (Myristacaceae). J. Ethnopharmacol 2009; 122: 406-409.

Hiruma-Lima CA., Spadari-Bratfisch RC., Kassisse DM., Souza-Brito ARM. Antiulcerogenic mechanisms of dehydrocrotonin, a diterpine lactone obtained from Croton cajucara. Planta Medica 1999; 65:325-330.

Hiruma-Lima CA., Gracioso JS., Toma W., Almeida ABA., Paula ACB., Brasil DSB., Muller AH., Souza-Brito ARM. Gastroprotective effect of cordatin, a diterpine isolated from Aparisthmium cordatum, on experimental gastric ulcer models in rats and mice. Phytomed 2001; 8: 94-100.

Hung CC., Tsai WJ., Kuo LMY., Kuo YH. Evaluation of caffeic acid amides analogues as antiplatelet aggregation and anti-oxidative agents. Bioorg Med Chem 2005; 13:1791-1797.

Irvine FR. Woody Plants of Ghana. London: Oxford University Press $; 1961$, p. 86

Iwu MM., Ayanwu BN. Phytotherapeutic profile of Nigerian Herbs: Antiinflammatory and Antiarthritic agents. J. Ethnopharmacol 1982; 6 (3): 263-274.

Konturek SJ., Kitler ME., Brzozovisk T., Radecki T. Gastric protection by merciadnol, a new synthetic flavoniod inhibiting histidine decarboxylase. Dig Dis Sci 1986a; 31: 847-852.

Konturek SJ., Radecki T., Brzozowski T., Drozdowicz D., Piastucki I., Tanaka M., Muramatsu M M., Aihara H. Antiulcer and gastroprotective effects of solon, a synthetic flavonoid derivative of sophoradin. Role of endogenous prostaglandins. Eur J. Pharmacol 1986b; 125: 185-192.

Latza S., Ganser D., Berger RG. Identification and accumulation of 1-D-glucopyranose in developing strawberry fruit (Fragaria ananassa Duch. Cv. Kent). J. Agric Food Chem 1996; 44:13671370.

Lewis WH., Elvin-Lewis MP. Medical Botany. New York: John Wiley and Sons; 1977, pp. 1-51.

Lewis DA., Hanson D Antiulcer drugs of plant origin. Prog Med Chem 1991; 28: 208-210.

Lorke D. A New Approach to Acute Toxicity Testing. Arch Toxicol 1983; 54, 275-287.

Liu M., Li XQ., Weber C., Lee CY., Brown J., Liu RH. Antioxidant and antiproliferative activities of raspberries J. Agric Food Chem 2002; 50 (10): 2926-2930.

Liu J., Wang X., Shigenaga MK., Yeo HC., Mori A., Ames BN. Immobilisation stress causes oxidative damage to lipid, protein, and DNA in brain of rats. J. Fed Amer Soc Exper Biol 1996;10: 1532-8.

Liu J., Mori A. Stress, ageing and oxidative damage, Neurochem Res 1999; 24:1479-97.

Manach C., Scalbert A., Morand C., Jimenez C. Bioavailability and bioefficay of polyphenols in humans. American J. Clin. Nutr 2004; 79:727-747.

Manach C., Scalbert A. Polyphenols and prevention of cardiovascular diseases. Curr Opin Lipidol 2005; 16:77-84.

Marıa AOM., Donadel O., Wendel GH., Guzman JA., Guerreiro E., Giordano OS. Gastric anti-ulcer activity of several $\alpha, \beta$-unsaturated carbonyl compounds in rats. Bio Pharm Bull 2000; 23: 555-557.

Melo PS., Durán N., Hiruma-Lima CA., Souza-Brito ARM., Ha M. Comparison of the Gastroprotective effects of diterpine lactone isolated from Croton cajura with its synthetic derivatives. J. Ethnopharmacol 2003; 87: 169-174.

Muanya CA. Natural Health- How Local Plants Help Boost Libido, by Researchers. The Guardian Newspaper Ltd; 2008, p. 24.

Muanya CA., Odukoya O A. Lipid peroxidation as index of activity in aphrodisiac herbs. J. Plant Sci 2008; 3(1): 92-98.
Mui T., Doteuchi M.Lipid peroxidation possible role in gastric damage-induced by ethanol in rats. Life sci 1986; 38: 2163-2167.

Nwafor PA., Bassey AI. Evaluation of the antidiarroeal and antiulcerogenic potential of ethanol extract of Carpolobia lutea leaves in rodents. J. Ethnopharmacol 2007; 111(3): 619-24.

Nwidu LL., Nwafor PA. Gastroprotective effects of leaf extracts of Carpolobia lutea (polygalaceae) G. Don. in rats. African J. Biotech 2009; 8 (12):15-19.

Nwidu LL, Nwafor PA., Cândida da Silva V., Rodrigues CM., Santos LC., Vilegas W. Anti-nociceptive effects of Carpolobia lutea G. Don (Polygalaceae) leaf fractions in animal models. Inflammopharmacol 20011; DOI 10.1007/s10787-010-0076-y.

Nwidu LL., Essien GE., Nwafor PA., Vilegas W. Antidiarrheal mechanism of Carpolobia lutea Leaf fractions in rats. Pharm. Biol 2011; 1-8, DOI: 10.3109/13880209. 2011.589854.

Oates PJ., Hakkinen JP. Studies of the mechanism of ethanolinduced gastric damage in rats Gastroenterol 1988; 94:10-21.

Oka S., Ogino K., Hobara T., Yoshimura H., Okazaki Y., Takemoto T., Ishiyaoa H., Imaizumi T., Yamasaki K., Kambe T. Role of active oxygen species in diethyldithiocarbamate-induced gastric ulcer in rat. Experentia 1990; 46: 281-283.

Oktay M., Gülçin I., Küfrevio glu ÖI. (2003). Determination of in vitro antioxidant activity of fennel (Foeniculum vulgare) seed extracts. Lebensmittel-Wissenchaft und Technologie 36: 263-271.

Pereira AS, Pereira AFM., Trugo LC., Aquino-Neto FR. Distribution of quinic acid derivates and other phenolic compounds in Brazilian propolis. Zeists Naturf C 2003; 58: 590-593.

Pihan G., Regillo C., Szabo S. Free radicals and lipid peroxidation in ethanol - and aspirin-induced gastric mucosal injury. Dig Dis Sci 1987; 32: 1395-1399.

Poulsen SS., Olsen SP., Kirkegaard P. Healing of cystaemininduced duodenal ulcer in rat. Dig Dis Sci. 1985; 30:161-167.

Rajan P., Vedernikova I., Cos P., Berghe DV., Augustyns K., Haemers A. Synthesis and evaluation of caffeic acids amides as antioxidants. Bioorg Med Chem Lett 2001; 11: 215-217.

Rice-Evans CA., Miller NJ., Paganga G. Structure antioxidant activity relationships of flavonoids and phenolic acids. Free Rad Bio Med 1986; 2: 933-956.

Rodrigues CM., Rinaldo D., Santos LC., Montoro P., Piacente S., Pizza C., Hiruma-Lima CA., Souza-Brito ARM., Vilegas W. Metabolic fingerprinting using direct flow injection spray ionisation tandem mass spectrometry for the characterisation of proanthocyanidins from the barks of Hancornia speciosa. Rapid Comm. Mass Spect 21: 1907-1914.

Salim AS. Role of oxygen derived free radicals in the mechanism of chronic gastric ulceration in rats; implication for cytoprotection. Digestion 1989; 1-2: 113-199.

Salim AS. Removing oxygen-derived free radicals stimulates healing of ethanol induced erosive gastritis in the rat. Digestion 1990; 47: $24-28$.

Samb B., Desai N., Nishtar S., Mendis S., Bekedam H., Wright A., Hsu J., Martiniuk A., Celletti F., Patel,K., Adshead F., McKee M., Evans T., Alwan A., Etienne E. Prevention and management of chronic diseases: a litmus test for the health system strengthening in low- income and middle- income countries. The Lancet 2010; 376 (9754):1785-1797.

Sairam K., Rao CV., Babu MD., Kumar KV., Agrawal VK., Goel RK.. Antiulcerogenic effect of methanolic extract of Emlica officinalis: an experimental study. J. Ethnopharmacol 2002; 82: 1-9.

Scalbert A., Manach C., Morand C., Jimenez L. Dietary polyphenols and the prevention of disease. Crit. Rev Food Sci Nutr 2005; 45: 87-306.

Schubert ML Gastric secretion. Gastroenterol 2000; 16: 463468. Saito M., Hosoyama H., Ariga T., Katapka S., Yamaji N. Antiulcer activity of grape seed extract and procyanidins. J. Agric Food Chem 1988; 46: 1460-1464.

Siddaraju MN., Shylaja DM. Inhibition of gastric $\mathrm{H}^{+}, \mathrm{K}^{+}$ ATPase and Helicobacter pylori growth by phenolic antioxidants of Zingiber officinale. Mol Nutr Food Res 2007; 5: 324-32.

Siddaraju MN., Shylaja DM., Inhibition of gastric $\mathrm{H}^{+} \mathrm{K}^{+}$ 
ATPase and Helicobacter pylori growth by phenolic antioxidants of Curcuma amada. J. Agric Food Chem, 2007b 55: 7377-7386.

Singh S., Majumdar DK. Evaluation of the gastric activity of fixed oil of Ocimum sanctum (Holy Basil). J. Ethnopharmacol 1999; 65: $13-19$.

Soll AH. Gastric, Duodenal and Stress Ulcers. In: Gastrointestinal Disease, Pathophysiology, Diagosis and Management, New York: Saunders; 1983, p. $278-295$.

Souza-Brito ARM, Rodriguez JA, Hiruma-Lima CA, Haun M, Nunes DS. Antiulcerogenic activity of trans-dehydrocrotonin from Croton cajucara Benth. Planta Medica 1988; 64: 126-129.

Szabo S.. Animal models of human diseases: cystaemin-induced acute and chronic duodenal ulcers in the rat. Amer. J. Pathol 1978; 93: 273- 276

Szabo S. Mechanism of mucosal injury in the stomach and duodenum: time sequence analysis of morphologic, functional, biochemical and histochemical studies. Scand J. Gastroenterol 1987; 22: $21-28$.

Takalgi T., Okabe S. The effects of drugs on the production and recovery process of stress ulcer. Jap J. Pharmacol 1968; 18: 9-18.
Yesilada E., Gurbuz I., Bedir E., Tatli I., Khan IA. Isolation of antiulcerogenic sesquiterpines lactones rom Centaure solstitialis L. spp solstitialis through bioassay- guided fractionation procedures in rats.J. Ethnopharmacol 2004; 95: (2-3): 213-219.

Yokozawa T., Chen CP., Dong E., Tanaka T., Nonaka GI., Nishioka I. Study on the inhibitory effect of tannins and flavonoids against the 1,1-diphenyl-2-picrylhydrazyl radical. Biochem Pharmacol 1998; 56:213-222.

Wallace JL. Recent advances in gastric ulcer therapeutics. Amer J Med 2001; 110,19S-22S

Wallace JL, Devchand PR. Emergency roles of for cyclooygenase- 2 in gastrointestinal mucosal defence. Brit J. Pharmacol 2005; 145: $275-282$.

Zaidi SH., Mukerji B. Experimental peptic ulceration (Part 1).The Significance of mucous barrier. Indian J. Med Res 1958; 46: 27-37.

Zhen W., Wang SY. Antioxidant activity and phenolic compounds in selected herbs. J. Agric Food Chem 2001; 49 (11): $5165-$ 5170 . 